\title{
PENGARUH KOPING ADAPTIF DAN MAL ADAPTIF TERHADAP DISMENOREA PADA MAHASISWI D III KEPERAWATAN, JAKARTA, TAHUN 2014
}

\author{
Yuli Mulyanti, Sri Maryani, Ermawati \\ yuli.mulyanti@yahoo.com \\ (Poltekkes Jakarta III, Prodi Keperawatan)
}

\begin{abstract}
Abstrak
Angka kejadian dismenore berkisar 45-95 persen. Wanita yang mengalami dismenore sampai parah dapat mencapai $15 \%$. Dismenore merupakan salah satu masalah ginekologi yang paling umum dialami wanita dari berbagai tingkat usia. Dismenore primer dialami oleh 60-75 \% wanita muda. Dari tiga perempat jumlah wanita tersebut mengalami dismenore dengan intensitas ringan atau sedang. Sedangkan seperempat bagiannya mengalami dismenore intensitas berat dan terkadang membuat penderitanya tidak dapat menahan rasa nyeri yang dialami. Penelitian ini bertujuan untuk mengindentifikasi pengaruh koping adaptif dan mal adaptif terhadap dismenore. Disain penelitian adalah deskripif dengan pendekatan Cross sectional, lokasi penelitian di Prodi D III Keperawatan. Pengambilan sampel dengan purposive sampling, jumlah sampel 71 responden..

Hasil penelitian didapatkan sebagian besar responden berusia 19 tahun 62,5\%, menstruasi pertama kali usia 13 tahun sebanyak 34,7\%, mengalami dismenore $84,7 \%$, dengan skala nyeri sedang $73,6 \%$, lokasi nyeri terbanyak adalah nyeri perut $86,7 \%$, Sedangkan koping adaptif terbanyak adalah mengeluh ke teman/ orang tua $66,7 \%$, dan koping mal adaptif marah-marah $40 \%$. Dengan uji statistik Chi square, didapatkan bahwa terdapat hubungan bermakna atau terdapat pengaruh koping mal adaptif (marah-marah) dan koping menangis terhadap sakit kepala pada saat menstruasi dengan $p$ value 0,002 dan 0,021 dengan nilai $\mathrm{OR}=$ 17,5 dan 7,656. Terdapat hubugan antara koping mal adaptif terhadap dismenore.
\end{abstract}

Kata kunci : dismenore, koping adaptif dan mal adaptif 


\title{
INFLUENCE OF MAL ADAPTIVE AND ADAPTIVE COPING TO DYSMENORRHEA
}

\author{
Yuli Mulyanti, Sri Maryani, Nurmilah \\ yuli.mulyanti@yahoo.com \\ (Jakarta III Health Politechnic, Major of Nursing)
}

\begin{abstract}
Abstrac
The incidence of dysmenorrhea ranges from 45-95 percent. Women who experience severe dysmenorrhea to be able to reach 15 percent. Dysmenorrhea or painful menstruation is one of the most common gynecological problems experienced by women of all ages .

Primary dysmenorrhea is experienced by 60-75\% of young women. Three quarters of women experience dysmenorrhea with mild or moderate intensity. While a quarter share of experiencing severe dysmenorrhea intensity and sometimes makes the sufferer unable to withstand the pain experience.

This study aimed to identify the influence of mal adaptive coping and adaptive to dysmenorrhea . Design research is a descriptive cross sectional approach, research sites in Prodi D III Nursing .The Sampling with purposive sampling, sample number 71 respondents .. The results showed most respondents experienced dysmenorrhea $84.7 \%$, with $73.6 \%$ moderate pain scale, the location of pain is abdominal pain $86.7 \%, 19$-year -old 62, 5\%, the menareche of age 13 years as much as $34.7 \%$. While most adaptive coping was complaining to a friend / parent $66.7 \%$, and mal adaptive coping $40 \%$. Chi square statistical test, it was found that there was a significant relationship or there are significant mal adaptive coping ( angry) and cry to headache during menstruation with $p$ value 0.002 and 0.021 with $O R=17.5$ and 7.656

There are relationship between mal adaptive coping to dysmenorrhea.
\end{abstract}

Key words : dysmenorrhea, mal adaptive and adaptive coping 


\section{Pendahuluan}

Menurut

Prawirohardjo (2007), Dismenore atau nyeri haid merupakan suatu rasa tidak enak di perut bawah sebelum dan selama menstruasi dan sering kali disertai rasa mual. Dismenorea merupakan gangguan saat mentruasi yang ditandai dengan adanya nyeri yang luar biasa sehingga tidak dapat melakukan aktivitas. Gejala yang mungkin terjadi adalah dengan adanya rasa nyeri yang seperti tertarik pada paha bagian dalam, mual-mual hingga muntah, sakit kepala dan pusing.

Dismenorea

disebabkan

karena rahim mengalami kontraksi.

Reaksi dari otot akan mempengaruhi prostaglandin. Prostaglandin akan mengalami peningkatan ketika awal menstruasi kemudian menurun setelah terjadi menstruasi sehingga mengakibatkan adanya rasa nyeri yang berkurang setelah hari pertama menstruasi.

Keluhan yang sering dialami adalah sakit atau ketidaknyamanan ketika mengalami haid. Angka kejadian (prevalensi) dismenorea berkisar 45-95 persen (sumber: USA,
November 2006). Wanita yang mengalami dismenorea sampai parah dapat mencapai 15 persen. Dismenorea atau menstruasi yang menimbulkan nyeri merupakan salah satu masalah ginekologi yang paling umum dialami wanita dari berbagai tingkat usia.

Dismenorea dibedakan menjadi dua yaitu dismenorea primer dan dismenorea sekunder. Dismenorea primer biasanya terjadi dari mulai pertama haid kurang lebih usia 10-15 tahun (menarche) sampai usia 25 tahun atau setelah wanita hamil dan melahirkan per vaginam. Nyeri pada dismenorea primer lebih dikarenakan karena kontraksi uterus.

Dismenoreaa primer terjadi beberapa waktu setelah menarke, biasanya sesudah menarke, umumnya sesudah 12 bulan atau lebih (Hanifa, 2005). Nyeri ini timbul sejak menstruasi pertama dan akan pulih sendiri dengan berjalanya waktu, tepatnya saat hormon tubuh lebih stabil atau perubahan posisi rahim setelah menikah dan melahirkan anak.

Dismenorea primer dialami oleh 60-75\% wanita muda. Dari tiga 
perempat jumlah wanita tersebut mengalami dismenorea dengan intensitas ringan atau sedang. Sedangkan seperempat bagiannya mengalami dismenorea intensitas berat dan terkadang membuat penderitanya tidak dapat menahan rasa nyeri yang dialami. Dismenorea kongestif dapat diketahui beberapa hari sebelum haid datang. Gejala yang ditimbulkan berlangsung 2 dan 3 hari sampai kurang dari 2 minggu. Pada saat haid datang, tidak terlalu menimbulkan nyeri. Bahkan setelah hari pertama haid, penderita dismenorea kongestif akan merasa lebih baik. Gejala yang ditimbulkan pada dismenorea kongestif, antara lain Pegal (pegal pada paha), Sakit pada payudara, lelah, mudah tersinggung, kehilangan keseimbangan, ceroboh, gangguan tidur, timbul memar di paha dan lengan atas.

Hasil penelitian Hendrik, 2006, pada buruh wanita usia produksi keluhan (responden 55 orang), didapatkan antara lain nyeri haid $58,18 \%$, nyeri perut bagian bawah $16,36 \%$, haid yang tidak teratur $41,82 \%$ dan nyeri pinggang $34,55 \%$.

Kurniawati, 2008, hasil penelitiannya didapatkan bahwa dismenorea mempengaruhi aktivitas siswi SMK Batik 1 Surakarta. Dari 85 siswi yang menjadi responden penelitian $61,7 \%$ di antaranya mengalami penurunan aktivitas sedangkan sisanya sebanyak $38,3 \%$ tidak mengalami penurunan aktivitas.

Nyeri dismenorea jika tidak segera diatasi akan mempengaruhi fungsi mental dan fisik individu sehingga mendesak untuk segera mengambil tindakan/terapi secara farmakologis atau non farmakologis. Penanganan dismenorea dapat dengan obat-obatan. Obat-obatan yang sering digunakan untuk mengatasi dismenorea adalah jenis obat NSAID (Non-streoid anti inflammantory drugs). Pengguna kontrasepsi pil biasanya digunakan untuk mengatasi nyeri haid. Bahkan kontrasepsi akan digunakan bersmaan dengan obat-obatan lainnya. Hal ini bertujuan untuk dapat mengurangi kadar estrogen. Adapula dismenorea yang 
disebabkan oleh fibroid maka akan dilakukan pengangkatan (operasi). Operasi uterine artery embolization. Pada kasus yang lebih parah, mungkin saja diperlakukan histerektomi. Tindakan histerektomi berupa pembedahan untuk mengangkatan seluruh uterus. Adapula cara penanganan lain dengan konsumsi suplemen vitamin B1, pemijatan dan akupuntur.

Cara yang lainnya dilakukan untuk mengurangi nyeri haid antara lain adalah : 1. Olahraga merupakan alternatif untuk anda meredakan nyeri. Lakukan olahraga rutin seperti jalan kaki, jongging, bersepeda dan berenang yang ternyata akan membantu anda menghasilkan senyawa kimia untuk menghambat nyeri yang luar biasa. 2. Berendam, Mandi dengan menggunakan air hangat atau dapat juga menggunakan botol yang diisi dengan air panas untuk dapat mengatasi nyeri anda. 3 . Istirahat cukup, Istirahat dapat anda lakukan dengan membiasakan tidur cukup sebelum dan selama periode menstruasi untuk membantu anda mengatasi rasa nyeri. 4. Relaksasi, Latihan yang dilakukan bisa berupa yoga. Yoga dapat menjadi cara anda mendapatkan relaksasi sehingga menanggulangi rasa nyeri.

Cara yang dilakukan individu dalam menyelesaikan masalah, menyesuaikan diri dengan perubahan serta respon terhadap situasi yang menngancam disebut dengan koping (Keliat, 1999).

Lazarus, 1985 koping adalah perubahan kognitif dan perilaku secara konstan dalam upaya untuk mengatasi tuntutan internal dan atau eksternal khusus yang melelahkan atau melebihi sumber individu. Koping adalah cara yang dilakukan individu dalam mengatasi masalah, mengatasi perubahan yang terjadi dan situasi yang mengancam baik secara kognitif maupun perilaku.

Stuart dan Sunden, 1995 membagi koping dalam dua kategori yaitu koping yang adaptif dan maladaptif. Koping yang adaptif adalah mekanisme koping yang mendukung fungsi integrasi pertumbuhan, belajar dan mencapai tujuan. Kategorinya ialah berbicara pada orang lain, memecahkan masalah secara efektif, tehnik relaksasi, latihan seimbang dan 
aktivitas konstruktif. Sedangkan koping yang maladaptif adalah koping yang menghambat fungsi integrasi, memecah pertumbuhan, menurunkan otonomi dan cenderung menguasai lingkungan. Kategorinya adalah makan berlebihan/tidak makan, bekerja berlebihan, menghindar. Tujuan penelitian ini adalah diperolehnya pengaruh koping adaptif dan maladaptif terhadap dismenorea pada mahasiswi Prodi D III Keperawatan Persahabatan.

Belum diketahuinya seberapa banyak perempuan yang mengalami dismenorea, bagaimana pengaruh koping yang digunakan terhadap kejadian dismenorea pada mahasiswi DIII Prodi Keperawatan Persahabatan? Apakah koping tersebut cukup efektif?. Oleh karena itu, untuk menjawab pertanyaan tersebut, maka akan dilakukan penelitian tentang pengaruh koping adaptif dan maladaptif terhadap dismenorea pada mahasiswi Prodi D III Keperawatan.

\section{Metodologi}

Disain penelitian ini adalah deskriptif, dengan pendekatan Cross sectional. Tempat penelitian dilakukan di Program Studi Keperawatan Persahabatan, Poltekkes Jakarta III. Waktu penelitian bulan Oktober sampai dengan Nopember 2014.

Populasi penelitian ini adalah mahasiswi D III Keperawatan Jalan Persahabatan, berjumlah 185 orang. Perhitungan sampel, dengan rumus (Notoatmodjo, 2007) di dapatkan jumlah sampel 65 orang. Untuk mengantisipasi drop out ditambahkan $10 \%$, sehingga jumlah sampel seluruhnya adalah 71 responden. Kriteria inklusi adalah mahasiswi yang sudah menstuasi dan bersedia menjadi responden, sedangkan kriteria eksklusi adalah mahasiswi yang tidak hadir dan mengalami gangguan kesehatan pada saat penelitian berlangsung. Tehnik sampling yang digunakan dengan purposive sampling. Instrumen penelitian berupa kuesioner.

Analisa data mencakup analisa univariat dan bivariat. Analisa univariat dilakukan untuk mendeskripsikan setiap variabel yang diukur dalam penelitian yaitu dengan melihat distribusi data pada semua 
variat. Sedangkan Uji bivariat dilakukan untuk melihat pengaruh koping adaptif dan maladaptif terhadap dimenorea. Uji statistik yang digunakan dengan uji Chi square

\section{Hasil}

Pada penelitian ini, hasil pengumpulan dan pengolahan data yang disajikan merupakan hasil analisis univariat dan bivariat.

Analisis univariat dilakukan untuk mengetahui distribusi responden berdasarkan beberapa variabel. Variabel dependen adalah dismenorea (skala nyeri dan lokasi nyeri) dan variabel independen adalah koping adaptif, koping mal adaptif. Berikut ini adalah hasil dari analisis univariat.

\section{Analisis Univariat}

Tabel 1.1

Distribusi Responden Menurut Keluhan Dismenorea dan Karakteristiknya

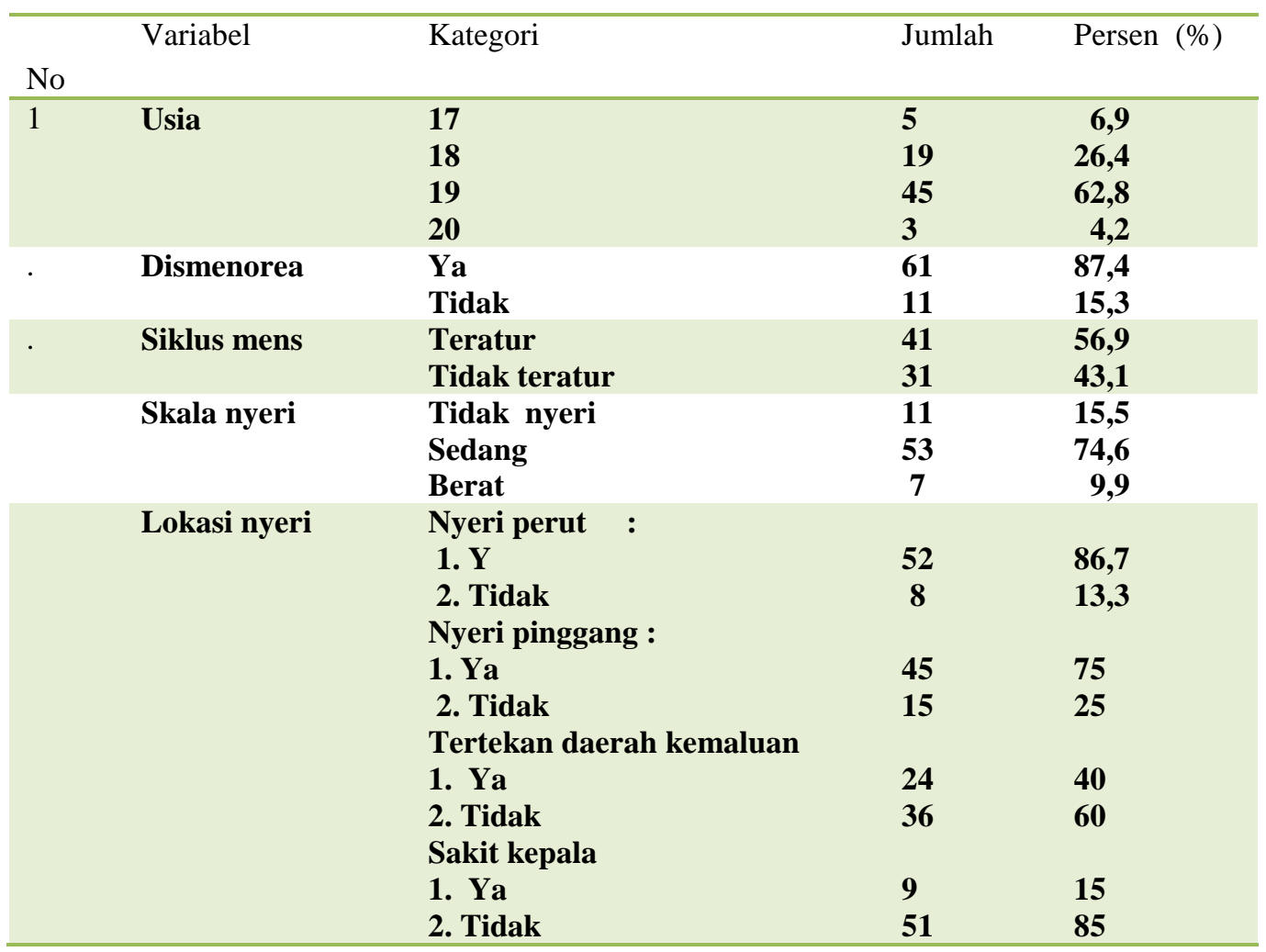


Berdasarkan tabel tersebut di atas diketahui bahwa, sebagian besar responden berusia 19 tahun sebanyak 62,8\%, mengeluh dismenorea $87,4 \%, \quad$ siklus menstruasi teratur $56,9 \%$, dengan skala nyeri sedang $74,6 \%$ dan lokasi nyeri terbanyak adalah pada daerah perut $86,7 \%$.

Tabel 1.2

Distribusi Responden Menurut Coping Adaptif

\begin{tabular}{|c|c|c|c|c|}
\hline No. & Variabel & Katego ri & Jumlah & Persen $(\%)$ \\
\hline \multirow[t]{3}{*}{1.} & Koping adaptif & \multicolumn{3}{|l|}{ Mengeluh ke teman/orang tua } \\
\hline & & 1. Ya & 40 & 66,7 \\
\hline & & 2. Tidak & 20 & 33,3 \\
\hline \multicolumn{5}{|c|}{ Tindakan yang dilakukan : nyeri perut } \\
\hline & & 1. Kompres hangat & 8 & 11,1 \\
\hline & & 2. Massage & 4 & 5,6 \\
\hline & & 3. Minum obat & 14 & 19,4 \\
\hline & & 4. Istirhat /tidur & 28 & 38,9 \\
\hline & & 5. Lainnya & 2 & 2,8 \\
\hline \multicolumn{5}{|c|}{ Efektifitas : } \\
\hline & & 1. Ya & 53 & 94,6 \\
\hline & & 2. Tidak & 3 & 5,4 \\
\hline
\end{tabular}

Tindakan yang dilakukan : nyeri pinggang :

1. Kompres hangat

2. Massage

3. Minum obat

4. Istirhat /tidur

5. Lainnya

1. Ya

2. Tidak

Tindakan yan dilakukan : tertekan area kemaluan
1. Minum obat

$4 \quad 5,6$

2. Istirahhat/tidur

$17 \quad 23,6$

3. Lainnya

$2 \quad 2,8$

Efektifitas :
1. Ya
$21 \quad 91,3$
2. Tidak
2
8,7

Tindakan yan dilakukan pada Nyeri kepala

1. Kompres hangat

2. Massage

3. Minum obat

4. Istirhat /tidur

,6
2,6

Efektifitas :
1. Ya
2. Tidak 
Tabel 1.3

Distribusi Responden Menurut Coping Mal Adaptif

\begin{tabular}{cllrr}
\hline No. $\quad$ Variabel & Katego ri & Jumlah & Persen $(\%)$ \\
\hline Kopin g mal adaptif : & & & & \\
1. Berteriak & 1. Ya & $\mathbf{8}$ & $\mathbf{1 3 , 3}$ \\
& 2. Tidak & $\mathbf{5 2}$ & $\mathbf{8 6 , 7}$ \\
2. Marah-marah & 1. Ya & $\mathbf{2 4}$ & $\mathbf{4 0}$ \\
& 2. Tidak & $\mathbf{3 6}$ & $\mathbf{6 0}$ \\
3. Menangis & 1. Ya & $\mathbf{2 3}$ & $\mathbf{3 8 , 3}$ \\
& 2. Tidak & $\mathbf{3 7}$ & $\mathbf{6 1 , 7}$ \\
4. Didiamkan & 1. Ya & $\mathbf{3 5}$ & $\mathbf{5 8 , 3}$ \\
& 2. Tidak & $\mathbf{2 5}$ & $\mathbf{4 1 , 7}$ \\
\hline
\end{tabular}

\section{Analisis Bivariat}

Analisis bivariat digunakan untuk menguji hubungan antara variabel independen (koping adaptif dan mal adaptif dengan variabel dependen yaitu dismenorea
Uji statistik yang digunakan adalah dengan uji Chi Square dengan tingkat kemaknaan 5\% $(\alpha=0,05)$. Hubungan dikatakan bermakna bila diperoleh nilai $\mathrm{p}<0,05$. Hasil analisis bivariat dapat dilihat pada tabel di bawah ini.

Tabel 2.1.

Distribusi Responden Berdasarkan Variabel Koping Adaptif Terhadap Lokasi Dismenorea

\begin{tabular}{lllll}
\hline No. $\begin{array}{l}\text { Koping } \\
\text { Adaptif }\end{array}$ & $\begin{array}{l}\text { Nyeri } \\
\text { perut }\end{array}$ & $\begin{array}{c}\text { Nyeri } \\
\text { pinggang }\end{array}$ & $\begin{array}{l}\text { Pyeri } \\
\text { tertekan } \\
\text { daerah } \\
\text { kemaluan }\end{array}$ & Sakit kepala \\
\hline $\begin{array}{l}\text { Melakukan } \\
\text { tindakan }\end{array}$ & 0,075 & 0,965 & 0,365 & 0,852 \\
$\begin{array}{l}\text { (Kompres hangat, } \\
\text { Massage, Minum } \\
\text { obat/jamu, } \\
\text { Istirahat/tidur) }\end{array}$ & & & \\
\hline $\begin{array}{l}\text { Mengeluh ke } \\
\text { teman/orang tua }\end{array}$ & 1,235 & 0,912 & 1,373 & 0,249 \\
\hline
\end{tabular}

Berdasarkan data tersebut, bahwa melakukan tindakan terhadap tidak terdapat hubungan dismenore dengan $\mathrm{p}$ value $>0,05$ bermakna antara koping adaptif 
Tabel 2.2

Distribusi Responden Berdasarkan Variabel Koping Mal Adaptif Terhadap Dismenorea /Nyeri Perut

\begin{tabular}{|c|c|c|c|c|c|c|c|c|}
\hline \multirow[t]{3}{*}{ No. } & \multirow[t]{3}{*}{ Koping } & \multicolumn{4}{|c|}{ Nyeri perut } & \multirow{3}{*}{$\begin{array}{l}\text { Jumlah } \\
(\%)\end{array}$} & \multirow{3}{*}{$\begin{array}{l}\mathbf{P} \\
\text { Value }\end{array}$} & \multirow[t]{3}{*}{ OR } \\
\hline & & \multirow{2}{*}{$\begin{array}{l}\text { Ya } \\
\text { Jumlah }\end{array}$} & \multirow[b]{2}{*}{$\%$} & \multicolumn{2}{|c|}{ Tidak } & & & \\
\hline & & & & Jumlah & $\%$ & & & \\
\hline \multirow[t]{3}{*}{1.} & Berteriak & & & & & & & \\
\hline & $>\mathrm{Ya}$ & 8 & 15,4 & 44 & 84,6 & 100 & 0,582 & 1,122 \\
\hline & $>$ Tidak & 0 & & 8 & 100 & 100 & & \\
\hline \multirow[t]{3}{*}{2.} & Marah-marah & & & & & & & \\
\hline & $>\mathrm{Ya}$ & 22 & 42,3 & 30 & 57,7 & 100 & 0,457 & 2,200 \\
\hline & $>$ Tidak & 2 & 25 & 6 & 75 & 100 & & \\
\hline \multirow[t]{3}{*}{3.} & Menangis & & & & & & & \\
\hline & - Ya & 23 & 44,2 & 29 & 55,8 & 100 & 0,019 & 0,558 \\
\hline & - Tidak & 0 & & 8 & 100 & 100 & & \\
\hline \multirow[t]{3}{*}{4.} & Di diamkan & & & & & & & \\
\hline & - Ya & 29 & 55,8 & 23 & 44,2 & 100 & 0,449 & 0,420 \\
\hline & - Tidak & 6 & 75 & 2 & 25 & & & \\
\hline
\end{tabular}

Berdasarkan hasil analisis bivariat, menunjukkan bahwa variabel koping mal adaptif / menangis berhubungan secara bermakna dengan dismenorea, $\mathrm{p}$ value $=0,019$ dengan $\mathrm{OR}=$ 0,558 artinya menangis digunakan sebagai koping pada saat dismenorea.

Tabel 2.3

Distribusi Responden Berdasarkan Variabel Koping Mal Adaptif Terhadap Dismenorea/ Nyeri Pinggang

\begin{tabular}{|c|c|c|c|c|c|c|c|c|}
\hline \multirow[t]{3}{*}{ No. } & \multirow[t]{3}{*}{ Koping } & \multicolumn{4}{|c|}{ Nyeri Pinggang } & \multirow{3}{*}{$\begin{array}{l}\text { Jumlah } \\
(\%)\end{array}$} & \multirow{3}{*}{$\begin{array}{l}\mathbf{P} \\
\text { Value }\end{array}$} & \multirow[t]{3}{*}{ OR } \\
\hline & & \multicolumn{2}{|c|}{ Ya } & \multicolumn{2}{|c|}{ Tidak } & & & \\
\hline & & Jlh & $\%$ & Jlh & $\%$ & & & \\
\hline \multirow[t]{3}{*}{1.} & Berteriak & & & & & & & \\
\hline & $>\mathrm{Ya}$ & 6 & 13,3 & 39 & 86,7 & 100 & 1,000 & 1,000 \\
\hline & $>$ Tidak & 2 & 13,3 & 13 & 86,7 & 100 & & \\
\hline \multirow[t]{3}{*}{2.} & Marah-marah & & & & & & & \\
\hline & $>\mathrm{Ya}$ & 21 & 46,7 & 24 & 53,3 & 100 & 0,78 & $\mathbf{3 , 5 0 0}$ \\
\hline & $>$ Tidak & 3 & 20 & 12 & 80 & 100 & & \\
\hline
\end{tabular}


3. Menangis

\begin{tabular}{|c|c|c|c|c|c|c|}
\hline - $\mathrm{Ya}$ & 16 & 35,6 & 29 & 64 , & 100 & 0,544 \\
\hline Tidak & 7 & 46,7 & 8 & $\begin{array}{l}53, \\
3\end{array}$ & 100 & \\
\hline
\end{tabular}

4. Di diamkan

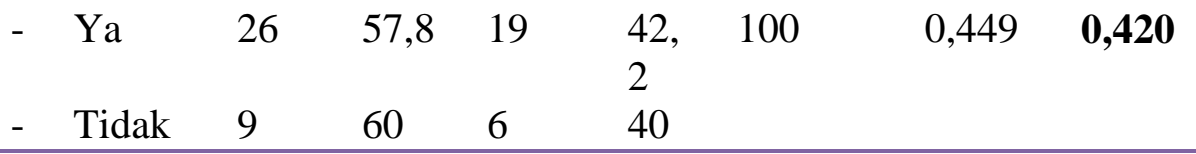

Berdasarkan data tersebut, bahwa adaptif terhadap skala nyeri tidak terdapat hubungan pada nyeri pinggang dengan $p$ bermakna antara koping mal value $>0,05$

Tabel 2.4

Distribusi Responden berdasarkan variabel Koping Mal adaptif terhadap Dismenorea/ Tertekan daerah Kemaluan

\begin{tabular}{|c|c|c|c|}
\hline \multirow{3}{*}{\multicolumn{2}{|c|}{ No. Koping }} & Tertekan daaerah kemaluan & \multirow[t]{3}{*}{$\mathbf{O R}$} \\
\hline & & & \\
\hline & & Jumlah & \\
\hline
\end{tabular}

1. Berteriak

$\begin{array}{lllllll}>\text { Ya } & 5 & 20,8 & 3 & 8,3 & 100 & 0,247 \\ >\text { Tidak } & 3 & 8,3 & 33 & 91,7 & & \end{array}$

2,895

2. Marah-marah

$\begin{array}{lccccccc}>\text { Ya } & 9 & 37,5 & 15 & 62,5 & 100 & 0,457 & \mathbf{2 , 2 0 0} \\ >\text { Tidak } & 15 & 41,7 & 21 & 58,3 & & & \end{array}$

3. Menangis

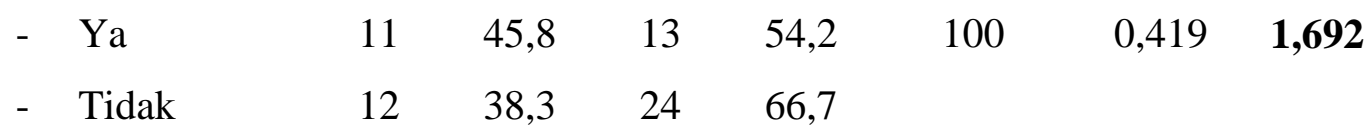

4. Di diamkan

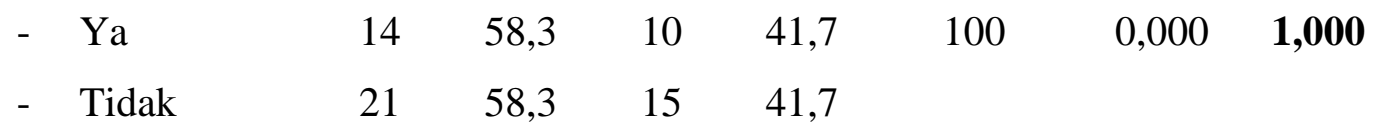


Berdasarkan data tersebut, bahwa

tidak terdapat hubungan

bermakna antara koping mal adaptif terhadap nyeri tertekan pada daerah kemaluan dengan $\mathrm{p}$ value $>0,05$

Tabel 2.5

Distribusi Responden Berdasarkan Variabel Koping Mal Adaptif Terhadap Dismenorea/ Sakit Kepala

\begin{tabular}{|c|c|c|c|c|c|c|c|c|}
\hline \multirow[t]{3}{*}{ No. } & \multirow[t]{3}{*}{ Koping } & \multicolumn{4}{|c|}{ Sakit Kepala } & \multirow{3}{*}{$\begin{array}{l}\text { Jlh } \\
(\%)\end{array}$} & \multirow{3}{*}{$\begin{array}{l}P \\
\text { Value }\end{array}$} & \multirow[t]{3}{*}{ OR } \\
\hline & & \multicolumn{2}{|c|}{ Ya } & \multicolumn{2}{|c|}{ Tidak } & & & \\
\hline & & Jlh & $\%$ & Jlh & $\%$ & & & \\
\hline \multirow[t]{2}{*}{1} & Berteriak & & & & & & & \\
\hline & $\begin{array}{l}>\text { Ya } \\
>\text { Tidak }\end{array}$ & $\begin{array}{l}2 \\
6\end{array}$ & $\begin{array}{l}22,2 \\
118\end{array}$ & $\begin{array}{l}7 \\
45\end{array}$ & $\begin{array}{l}77,8 \\
882\end{array}$ & 100 & 0,593 & 2,14 \\
\hline
\end{tabular}

2. Marah-marah

$\begin{array}{lccccccc}>\text { Ya } & 8 & 88,9 & 1 & 11,1 & 100 & \mathbf{0 , 0 0 2} & \mathbf{1 7 , 5 0 0} \\ >\text { Tidak } & 16 & 31,4 & 35 & 68,6 & & & \end{array}$

3. Menangis

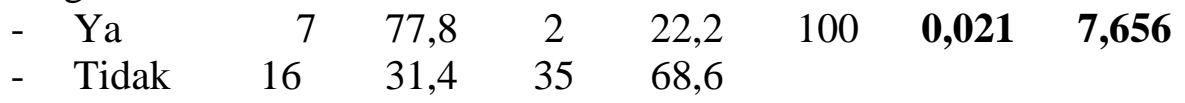

4. Di diamkan

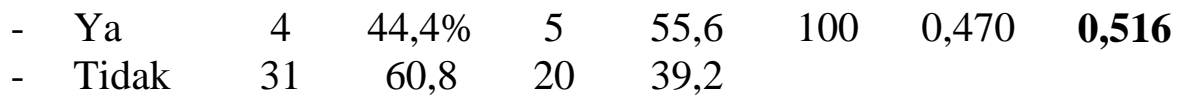

Berdasarkan tabel di atas menangis terhadap nyeri kepala didapatkan, bahwa terdapat dengan $\mathrm{p}$ value masing-masing hubungan bermakna antara 0,002 dan 0,021.

koping marah-marah dan

\section{Pembahasan}

$\begin{array}{clrlr}\text { Koping } & \text { adalah cara yang } & \text { menyelesaikan } & \text { masalah, } \\ \text { digunakan } & \text { individu } & \text { dalam } & \text { menyesuaikan diri dengan perubahan }\end{array}$


serta respon terhadap situasi yang mengancam. Stuart dan Sunden, 1995 membagi koping dalam dua kategori yaitu koping yang adaptif dan maladaptif.

Koping yang adaptif adalah mekanisme koping yang mendukung fungsi integrasi pertumbuhan, belajar dan mencapai tujuan. Kategorinya ialah berbicara pada orang lain, memecahkan masalah secara efektif, tehnik relaksasi, latihan seimbang dan aktivitas konstruktif.

Sedangkan koping yang
maladaptif adalah koping yang
menghambat fungsi integrasi,
memecah pertumbuhan, menurunkan
otonomi dan cenderung menguasai
lingkungan. Kategorinya adalah
makan berlebihan/tidak makan,
bekerja berlebihan.

Hasil penelitian didapatkan koping adaptif yang banyak digunakan adalah mengeluh ke teman sebanyak $66,7 \%$. Usia responden berkisar antara 17-20 tahun, pada usia tersebut merupakan usia remaja akhir, dimana pada usia tersebut remaja lebih sering berkumpul bersama kelompoknya dan lebih terbuka dengan kelompoknya dibandingkan dengan orang tua.

Sedangkan dari segi tindakan yang dilakukan, sebagian besar responden lebih memilih untuk beristirahat atau tidur untuk mengatasi rasa nyeri yang datang saat menstruasi mencapai $50 \%$. Sedangkan koping mal adaptif yang banyak digunakan pada saat nyeri haid adalah marah-marah sebanyak $40 \%$ dan koping menangis sebanyak $38,3 \%$

Sebagian besar responden mengalami dismenorea sebanyak $84,7 \%$, usia saat haid pertama kali pada usia 13 tahun sebanyak 34,7\%. Adapun karakteristik dismenorea pada responden didapatkan, bahhwa sebagian besar responden mengalami nyeri haid dengan skala nyeri sedang sebesar 73,6\%, siklus haid teratur $55.6 \%$ dan ditinjau dari jumlah haid sebagian besar jumlah haidnya adalah sedang 54\%. Lokasi nyeri haid terbanyak adalah nyeri perut sebesar $86,7 \%$. 
Studi epidemiologi pada populasi remaja (berusia 12-17 tahun) di Amerika Serikat, Klein dan Litt melaporkan prevalensi dismenorea mencapai59,7\%. Dari mereka yang mengeluh nyeri, $12 \%$ berat, $37 \%$ sedang, dan $49 \%$ ringan. Puncak insiden dismenorea primer terjadi pada akhir masa remaja (adolescence) dan di awal usia 20-an, insiden dismenorea pada remaja (adolescence) dilaporkan sekitar 92\%. Insiden ini menurun seiring dengan bertambahnya usia dan meningkatnya kelahiran (Anurogo, 2008).

\section{Lowdermilk, 2013 wanita dewasa muda usia 17-24 tahun adalah yang paling sering melaporkan haid yang terasa nyeri. Sekitar $75 \%$ wanita melaporkan berbagai derajat ketidaknyamanan yang berhubungan dengan menstruasi.}

Hasil penelitian Hendrik, 2006, pada buruh wanita usia produksi keluhan (responden 55 orang), didapatkan antara lain nyeri haid $58,18 \%$, nyeri perut bagian bawah $16,36 \%$, haid yang tidak teratur $41,82 \%$ dan nyeri pinggang $34,55 \%$.

Dari data tersebut menunjukan bahwa sebagian besar responden mengalami dismenorea sebanyak $84,7 \%$.

Ditinjau dari lokasi nyeri terdapat perbedaan penelitian hendrik lokasi nyeri terbanyak adalah nyeri pinggang sedangkan hasil penelitian ini didapatkan, bahwa sebagian besar responden merasakan nyeri pada area perut sebanyak $86,7 \%$.

Penelitian menunjukkan bahwa dismenorea memiliki dasar biokimia dan terjadi akibat pelepasan prostaglandin, Selama fase luteal dan aliran menstruasi berikutnya, prostaglandin $\mathrm{F}_{2}$ alfa (PG F2 $\underset{2}{\alpha}$ ) yang berlebihan meningkatkan amplitudo dan frekuensi kontraksi uterus, sehingga menyebabkan vasopasme arteriol uterus, sehingga mengakibatkan iskemia dan kram abdomen bawah yang bersifat siklik. Respon iskemik PG F2a meliputi nyeri punggung, kelemahan, pengeluaran keringat, gejala saluran cerna ( anoreksia, mual, muntah dan diare)dan gejala sistem saraf pusat 
(pusing, sinkop, nyeri kepala dan konsentrasi buruk), namun pengeluaran prostaglandin yang berlebihan tidak diketahui penyebabnya. (Bobak, 2005).

Selama menstruasi, sel-sel endometrium yang terkelupas, melepaskan prostaglandin, yang menyebabkan iskemia uterus melalui kontraksi miometrium dan vasokonstriksi. Peningkatan kadar prostaglandin telah terbukti ditemukan pada cairan haid (menstrual fluid) pada wanita dengan dismenoreaa berat. Kadar ini memang meningkat terutama selama dua hari pertama menstruasi. Vasopressin juga memiliki peran yang sama (Anugroho, 2008).

Yang menjadi fokus perhatian adalah seberapa rendah atau tingginya ambang nyeri dalam tubuh dalam merespon kenaikan prostaglandin tersebut. (Yusi, 2009)

Dismenorea adalah nyeri selama menstruasi yang disebabkan kejang otot uterus (Sylvia Anderson, 2005). Menstruasi yang menyakitkan, terutama terjadi pada perut bagian bawah dan punggung, biasanya terasa seperti kram (Helen Verney dkk, 2006)

Dismenorea atau nyeri haid, gangguan ini sifatnya subjektif, berat atau intensitasnya sukar dinilai. Walaupun frekuensi dismenorea cukup tinggi dan penyakit ini sudah lama dikenal, namun sampai sekarang patogenesisnya belum dapat dipecahkan dengan memuaskan (Hanifa, 2008). Faktor kejiwaan juga merupakan salah satu faktor yang mempengaruhi dismenorea pada wanita muda yang secara emosional tidak stabil, apalagi jika mereka tidak mendapat pengetahuan yang baik tentang proses haid, akan mudah mengalami dismenorea.

Hasil uji bivariat didapatkan terdapat hubungan yang bermakna antara koping mal adaptif marahmarah dan menangis terhadap dismenorea, dengan $\mathrm{p}$ value masingmasing 0,002 dan 0, 021 artinya terdapat pengaruh koping marahmarah dan menangis terhadap dismenorea pada mahasiswa DIII Keperawatan Jakarta. 
Hal ini berbeda dengan hasil penelitan Haryani, 2012 dan Saidah, 2012 koping yang digunakan saat menstruasi adalah koping adaptif.

Ditinjau dari metode koping yang digunakan responden yaitu marah-marah dan menangis merupakan metode jangka pendek, cara ini digunakan untuk mengurangi stress atau ketegangan psikologis dan cukup efektif untuk waktu sementara, tetapi tidak efektif untuk di gunakan dalam jangka panjang.

Pada dasarnya mekanisme pertahanan diri terjadi tanpa disadari dan bersifat membohongi diri sendiri terhadap realita yang ada, baik realita yang ada diluar (fakta atau kebenaran) maupun realita yang ada di dalam ( dorongan atau impuls atau nafsu). Mekanisme pertahanan bersifat menyaring realita yang ada sehingga individu bersangkutan tidak bisa memahami hakekat dari keseluruhan realita yang ada. Ini membuat sebagian besar ahli menyatakan koping jenis mekanisme pertahanan diri merupakan yang tidak sehat kecuali sublimasi
Mekanisme pertahanan tidak dapat disadari, akan dapat disadari melalui refleksi diri yang terus menerus. Dengan cara begitu individu bisa mengetahui jenis mekanisme pertahanan diri yang biasa dilakukan dan kemudian menggantikannya dengan koping yang lebih konstruktif.

Penataan dismenorea primer tergantung pada beratnya masalah dan respons individual wanita terhadap berbagai pengobatan. Komponen penting dari asuhan keperawatan adalah informasi dan dukungan. Karena menstruasi sangat berhubungan dengan reproduksi dan seksualitas. Masalah menstruasi seperti dismenore dapat memberi pengaruh negatif bagi seksualitas dan penghargaan diri. Mitos-mitos dan informasi yang salah tentang menstruasi dan dismenore dapat dikurangi dengan memberikan faktafakta tentang proses menstruasi dan merupakan hal yang normal terjadi bagi setiap wanita. 


\section{Simpulan}

Karakteristik responden, usia berkisar antara 17-20 tahun. Sebagian besar responden mengalami dismenorea sebanyak $84,7 \%$, usia saat haid pertama kali pada usia 13 tahun sebanyak 34,7\%. Sebagian besar responden mengalami nyeri haid dengan skala nyeri sedang sebesar $73,6 \%$, siklus haid teratur $55.6 \%$ dan ditinjau dari jumlah haid sebagian besar jumlah haidnya adalah sedang 54\%. Lokasi nyeri haid terbanyak adalah nyeri perut sebesar $86,7 \%$.

Koping adaptif yang banyak digunakan adalah mengeluh ke teman sebanyak 66,7\%. Dari segi tindakan yang dilakukan, sebagian besar responden lebih memilih untuk beristirahat atau tidur untuk

\section{Saran}

Perawat dapat memberikan informasi dan dukungan tentang dismenorea. Dengan adanya informasi yang adekuat serta penanganannya, persepsi terhadap mengatasi rasa nyeri yang datang saat menstruasi mencapai $50 \%$.

Koping yang banyak digunakan saat menstruasi adalah koping mal adaptif yaitu marahmarah sebanyak $40 \%$ dan koping menangis sebanyak $38,3 \%$

Terdapat pengaruh koping marah-marah dan menangis terhadap nyeri kepala pada saat dismenorea. Mekanisme pertahanan tidak dapat disadari, akan dapat disadari melalui refleksi diri yang terus menerus. Dengan cara begitu individu bisa mengetahui jenis mekanisme pertahanan diri yang biasa dilakukan dan kemudian menggantikannya dengan koping yang lebih konstruktif. Terdapat hubungan antara koping mal adaptif terhadap dismenore.

dismenore menjadi positif, sehingga koping yang digunakan digantikan dengan koping yang lebih konstruktif. Disarankan perlu dilakukan penelitian tentang penanganan yang efektif terhadap dismenorea. 


\section{Daftar Pustaka}

Alimul, H. aziz. 2007. Riset Keperawatan \& Teknik Penulisan Ilmiah. Jakarta : Salemba Medika

Bobak, Irene. M. 2005.Keperawatan Maternitas. Jakarta : EGC

Brockopp and Tolsma. 2000. Dasardasar Riset Keperawatan. Jakarta : EGC

Dismenore, Gangguan Saat

$\underline{\text { Menstruasi }}$

http://bidanku.com/dismenoregangguan-saatmenstruasi\#ixzz2wTRt30UG

Gail W. Stuart. 2006. (Ed. 5.Cet 1).

Buku Saku Keperawatan Jiwa. Jakarta : EGC

Hanifa, 2005. Ilmu Kebidanan Jakarta : Yayasan Bina Pustaka Sarwono Prawirohardjo

Hendrik, 2006.

http://keperawatan.unsoed.ac.i
d/sites/default/files/BAB\%20I $\underline{-\mathrm{V} . \mathrm{pdf}}$

Kristina agustiningsih. https://www.blogger.com/prof ile/17383112810771483980.

Kurniawati. 2011.

Journal.unnes.ac.id > Home > Vol 6, No 2 (2011) >

Lowdermilk, Perry and Cashion. 2013. Keperawatan Maternitas. Jakarta : Salemba Medika

Manuaba, Ida Bagus Gede. 2001. Kapita Selekta

Penatalaksanaan Rutin

Obstetri Ginekologi dan KB. Jakarta : EGC

Nursalam. 2011. (Edisi 2). Konsep dan Penerapan Metodologi Penelitian Ilmu Keperawatan. Jakarta: Salemba Medika.

Rasmun, 2004. Stres, Koping dan Adaptasi, Sagung Seto, Jakarta.

Siswanto.2004 Kesehatan Mental, konsep, cakupan dan perkembangannya. CV. Andi Offeset, Yogyakarta 